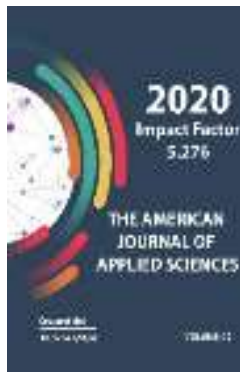

Journal Website: http://usajournalshub.c om/index,php/tajas

Copyright: Original content from this work may be used under the terms of the creative commons attributes 4.0 licence.

\section{Features Of Teaching Physics In Higher And General Medical Educational Institutions}

\author{
Lola Khamidovna Zoirova \\ Candidate Of Physical And Mathematical Sciences, Associate Professor, Department Of \\ “General Physics", Navoi State Mining Institute, Uzbekistan \\ Ozoda Akbar Kizi Phayzullayeva \\ Student Of The Power Engineering Faculty, Navoi State Mining Institute, Uzbekistan \\ Shohzod Odiljon Ugli Ubaydullayev \\ Student Of The Power Engineering Faculty, Navoi State Mining Institute, Uzbekistan \\ Malika Yunusjon Kizi Rakhimova \\ Student Of The Power Engineering Faculty, Navoi State Mining Institute, Uzbekistan
}

\title{
ABSTRACT
}

The article presents the main reasons and the need for highly qualified specialists in the field of physics, as well as radiation medicine.

\section{KEYWORDS}

Top-level specialist, methods and methods of teaching physics, need, radiation physics, pedagogical competence, motivation, diagnostics, practical and laboratory work.

\section{INTRODUCTION}

It is widely known that innovative education is aimed at training new-the highest and most necessary level of specialists who are able to skillfully analyze, summarize and systematize the available information, generate new knowledge, implement the results of scientific research (new devices, technologies, medicines, etc.), and increase the competitiveness of enterprises and institutions. Today, it is especially important to improve the quality of medical training and education.

At this stage, especially during the developing COVID-19 pandemic, special attention should be paid to the methods of teaching physics in medical higher and General professional educational institutions. The growth of 
students ' motivation to study physics contributes to the laboratory practice using medical equipment used in the diagnosis and treatment of diseases. The skills of automated computing are subsequently successfully used by senior students in the implementation of research projects in the field of professional interests, where medical and biological physics, methods of teaching physics, laboratory practice, etc. play an important role.

Currently, existing and rapidly developing new high-tech methods of diagnosis and treatment of diseases, such as x-ray, magnetic resonance, positron emission tomography and various types of radiosurgery that use ionizing radiation to affect pathological tissues and others. In this regard, the requirements for the level of professional training of future doctors are constantly increasing. The physical foundations of diagnostic methods and processes that occur in the body when exposed to external radiation are laid by medical students in specialized Universities in medical and biological physics classes.

Students' motivation to study physics is increased by conducting a laboratory workshop using medical equipment used in the diagnosis and treatment of diseases. Lectures on physics and medical biological physics cover the following sections: mechanical waves, their effect on the body, and the use of a variety of these waves in medicine; fundamentals of hydro - and hemodynamics; biological membranes and membrane potentials; electromagnetic fields and fundamentals of electrocardiography; fundamentals of quantum optics and physics of atoms and molecules; elements of radiobiology. All lectures are conducted using multimedia presentations. The most difficult topics for students are related to the transport of particles through biological membranes (transport phenomena) and the mechanisms of formation of membrane potentials; modeling of electrical activity of organs and the basics of quantum physics. This is partly due to the use of unusual for first - year students of the mathematical apparatus of higher school and the novelty of the material, and to a certain extent-the lack of systematic knowledge of the secondary school program, and as a result, the inability to apply the laws of physics to problems of an applied nature. The most difficult questions of theoretical material are additionally considered in practical classes. Part of the laboratory workshop consists of standard physics papers on various topics. Nevertheless, the task of each laboratory work is to study the basic physical laws and phenomena used in this study, their application to solving problems of medical and biological profile, mastering the methods of conducting educational and scientific experiments, and conducting mathematical processing of measurement results with subsequent formulation of conclusions. The peculiarity of laboratory work is to obtain results that generally differ greatly from one person to another. These laboratory works are of particular interest to students, as they are as close as possible to the practical work of a doctor. Students gain experience working with medical devices and learn how to formulate a medical report. At the initial stage, students should pay special attention to the typical mistakes they make when performing laboratory tasks. These include: determining the price of division and measuring device readings; selecting the scale and plotting the dependence of the studied value; performing calculations with powers of numbers, etc.

A detailed analysis of the quality of training of University graduates shows that the creation of high-tech work programs, optimal plans for lectures, practical classes, seminars, workshops and other types of educational activities of students does not always lead to the desired end result - obtaining a highly qualified young specialist. This depends on many social and economic factors, as well as on 
the level of basic training of applicants and the correct choice of their future profession.

Students still have insufficiently developed communication skills, many mechanisms of self-regulation and self-organization are reduced, which is manifested in a significant part by the inability to take notes on lecture material, the inability to Express their thoughts aloud, and to make clear structured reports. Much attention in teaching is paid to lecture and seminar forms of training with mandatory intermediate certification.

However, the main ones are practical classes, where the teacher has the opportunity to conduct individual work. From the first days of training, students under the guidance of teachers adapt to the working conditions in the physical laboratory. Modern electronic learning tools and such areas as information and communication technologies, multimedia technologies, and distance learning are becoming increasingly important in the educational sphere. Science is developing in this direction very intensively, because information technologies open up completely new dimensions of human consciousness, form a different way of thinking, and create new opportunities for understanding the world around us.

\section{RELEVANCE}

The basis of information technologies for teaching physical disciplines is computer training, which allows you to model physical and chemical processes, technical devices, and physical phenomena. Sets of didactic materials on the course of General, practical, classical, quantum, atomic, nuclear, biological and radiation-medical physics were created. These sets are presentations that are a sequence of slides related to a common theme, and multimedia fragments that show the dynamics of the corresponding physical processes and phenomena. Most often, these are difficult to understand sections: the mechanism of electrolytic dissociation; mechanisms of chemical bond formation, hybridization of electron clouds, and mechanisms of physical processes (transport mechanisms). These didactic materials allow us to replace outdated visual teaching tools, such as tables, magnetic boards, filmstrips, and movies, and to consider complex physical radiation processes in stages and dynamics. The mechanisms of many of them are much better understood and remembered by students, since they arouse a keen interest in the material, and therefore in physical disciplines, which significantly affects the quality and effectiveness of the educational process.

\section{THE MAIN FINDINGD AND RESULTS}

The rapid development of computer technologies has made it possible to develop and apply electronic textbooks in the learning process, which are much more accessible than printed textbooks or conventional forms of education. Computer technologies are a modern source of information, a visual aid, an individual information space, a simulator, and a control tool that can significantly improve the quality of education. In addition, the presence of a screen at lectures or seminars allows you to make interactive elements, conduct control surveys and testing on situational tasks, give tasks, etc. At the same time, the use of information computer technologies contributes to a significant increase in the level of knowledge of students, and teachers increase the time for individual creative work. At the same time, it should be remembered that a teacher can not only be a transmitter of knowledge, skills and information, he must be a teacher, a psychologist, and a psychotherapist.

The practical part is represented by a laboratory workshop and mastering the methods of conducting biochemical analyses necessary for performing research work. At the 
same time, much attention is paid to the rules of safe work in the physical laboratory. In the course of training, students gain skills to work on modern biochemical equipment: photoelectrocalorimeter, spectrophotometer, the instrument, the refractometer. This educational process contributes to the acquisition of not only in-depth knowledge of physical disciplines, but also to mastering practical skills in the physical laboratory. Our experience shows that the main incentive in the study of physical disciplines is the formation of interest based on specific examples of the use of knowledge and methods in clinical practice.

It is particularly necessary to emphasize that the educational process in this direction also allows you to effectively conduct research. In the future, research work of students $(R \& d)$ is an important means of improving the quality of training of future medical specialists, allows you to direct the scientific and labor potential of students to solve the most important problems of modern healthcare.

Also, in practice, it is important to widely apply the most effective and latest teaching methods, both individually and in a mixed version, such as: "Brainstorming", "Blitz survey", "Case technology", "fish Skeleton", "Question-and-answer conversation", "Venn Diagram" and many others. We must not forget that the teaching factor itself is important in teaching-that is, an individual approach to each student.

Also, the organizational and methodological foundations for ensuring radiation safety comment on the following concepts and phenomena:

- Requirements for ensuring radiation safety of the population;

- Basic principles of radiation safety;

- Control of man-made irradiation of the population;
- Control of natural exposure of the population;

- Permissible levels of radiation at construction sites;

- Requirements for the quality of drinking water;

- Requirements for the quality of food;

- Organization of radiation protection of the population;

- Management decisions to protect the population under normal radiation conditions;

- Planning for the protection of NPP personnel and the public;

- Creation of an operational local notification system;

- Engineering and technical measures to ensure the safe operation of nuclear power plants;

- Preparation of protective structures to shelter personnel and the public in the event of an accident at a nuclear power plant;

- Providing NPP personnel and the public with personal protective equipment;

- Construction of a road network in the nuclear power plant area;

- Creation of safety zones around nuclear power plants;

- Maintaining constant readiness of forces and means to eliminate the accident;

- Preparation of facility personnel and the public for actions in conditions of radiation contamination;

- Monitoring of the radiation situation;

- Management decisions to protect the population in the event of a radiation accident;

- Actions of management bodies in the event of an accident at a nuclear power plant;

- Operational forecasting of the consequences of an accident and making decisions to protect the population, etc. 


\section{CONCLUSION}

Practice shows that due to the situation around the world (the global COVID-19 pandemic), it is very promising to use elearning opportunities in the educational process and gradually switch from traditional learning to web-based learning and then to mixed learning. But to do this, a huge database of electronic resources on Biophysics must be formed (e-books, textbooks, videos, simulation processes showing physical processes and phenomena, etc.).

Thus, the study of medical and biological physics provides medical students with the basis of the physical picture of the world necessary for the study of subsequent professional disciplines, and contributes to the education of a competent specialist doctor who relies on the fundamental laws of nature in his work.

\section{REFERENCES}

1. Vlasova L.V., Yaglitskaya N.N., Tsapok P.I. Innovations that facilitate the adaptation of new generation first-year students in the study of physical disciplines in medical schools //Pedagogy and psychology in the XX1 century: current state and research trends. Materials of the Second all-Russian (correspondence) scientific and practical conference with international participation (December 25-26, 2014, Kirov [electronic resource]). - 2015. - p. 23-29.

2. Kokina N.V., Yurkin V.M. / / Scientific and educational space: development prospects: materials of the IV international conference. scientific-practical Conf. Cheboksary: Interactive plus, 2017. - P. 140144.

3. Tereshko T.A. Innovative education in higher education / T.A. Tereshko // Training of highly qualified scientific personnel in the context of innovative development of society: Proceedings of the International. nauch-prakt. konf. - Mn.: GU "BelISA", 2009. - P. 242-244.

4. Shatravko N.S. Active teaching methods as a factor in the formation of innovative pedagogical activity of teachers / / Prospects for the development of higher education: Materials of the 2nd international conference. scientific method, Conf. - Grodno: GGAU, 2009. - P. 127-131.

5. Askarova Y., Korableva Z. Pedagogy maarat asoslari (Muammoli maruzalari Mati). Namangan -2005 yil, Pp. 30-36.

6. Khodzhabaev A.R., Khasanov I.A., Nishonaliev U.N. Casby e-education of metodologias UV thanme. Toshkent-2006. P. 58-61.

7. Hemp E. F. and others. Radiobiology. Encyclopaedic dictionary. Gomel, 2005, P. 252.

8. Kudryashov Yu.B., Berenfeld B.S. Radiation Biophysics, M., 1979. P. 145-148.

9. Lastovkin V.F. Fundamentals of radiation safety. Textbook. Nizhny Novgorod, 2017, P. 48-52.

10. Blyakhman F.A., Teleshev V.A. Teaching physics at a medical University. System approach. Article. Higher education in Russia, No. 10, 2010, P. 152-155.

11. Nechaeva V.G., Shevchenko E.V., Voronova L.K., Korzhuev A.V. Teaching physics at a medical University: history and modernity. Siberian medical journal. No. 7, 2010. P. 3639. 